\author{
() Е.В. Бирюкова
}

Московский государственный медико-стоматологический университет им. А.И. Евдокимова, Москва

Стремительному постарению населения планеты сопутствует масштабная эпидемия сахарного диабета 2 типа (СД2). С возрастом значительно увеличивается распространенность СД2. Целью настоящего обзора стало обобщение данных литературы о СД2 в пожилом и преклонном возрасте. Представлены основные гериатрические синдромы, которые следует учитывать при ведении пациентов старшего возраста (когнитивные нарушения, саркопения, ортостатическая гипотензия, падения, недержание мочи, старческая астения и др.). Анализируются причины для высокого риска развития гипогликемии в пожилом возрасте. Совершенствование подходов к терапии Сд2 - приоритетная проблема современной медицины. Сахароснижающая терапия особенно сложна в популяции людей пожилого и старческого возраста из-за повышенного риска гипогликемии, наличия многочисленных сопутствующих заболеваний, проблемы полипрагмазии. Особое внимание уделено рекомендациям по лечению. Основные требования к сахароснижающим препаратам, применяемым у лиц пожилого возраста: низкий риск развития гипогликемий, отсутствие нефро-, гепатотоксичности, сердечно-сосудистая безопасность и простой режим приема. Обсуждаются преимущества и ограничения применения различных групп сахароснижающих препаратов у пациентов пожилого возраста. Подробно рассматривается группа дипептидилпептидазы 4 типа (ДПП-4). Представлены современные данные о механизмах сахароснижающего действия ингибиторов ДПП-4. Рассмотрены возможности использования ситаглиптина у пациентов пожилого возраста. Обсуждается доказательная база ситаглиптина, демонстрирующая очевидные преимущества препарата в лечении СД2 в пожилом возрасте.

КЛЮЧЕВЫЕ СЛОВА: сахарный диабет 2 типа; пожилой возраст; преклонный возраст; гериатрические синдромы; гипогликемии; сахароснижающая терапия; ингибиторы ДПП-4; ситаглиптин

\title{
TYPE 2 DIABETES MELLITUS IN ELDERLY PATIENTS TREATED WITH ENDOCRINOLOGISTS IN CLINICAL PRACTICE
}

\author{
(c) Elena V. Biryukova
}

Moscow State University of Medicine and Dentistry named after A.I. Evdokimov, Moscow, Russia

A large-scale epidemic of type 2 diabetes mellitus (T2DM) is observed with advanced ageing worldwide. The prevalence of T2DM significantly increases with age. Therefore, this review aimed to summarise the data on T2DM in advanced and older aged patients. The primary geriatric syndromes, which should be considered for the management of older patients (cognitive impairment, sarcopenia, orthostatic hypotension, falls, urinary incontinence, senile asthenia, etc.), are presented. The causes of the high risk for hypoglycaemia in elderly patients are analysed. Improving the treatment for T2DM is a priority of modern medicine. Using antihyperglycaemic therapy is especially difficult in this population due to the high risk of hypoglycaemia and the multi-organ pathology leading to polypharmacy. Therefore, special attention is paid to treatment recommendations. Hypoglycaemic drugs used in elderly patients should be low risk of hypoglycaemia, without nephro- and hepatic toxicity, safe for cardiovascular organs, easy to administer. Furthermore, advantages and limitations of using various groups of hypoglycaemic drugs in elderly patients are discussed. DPP-4 inhibitors are also considered in detail. Modern data on mechanisms of hypoglycaemic action of DPP-4 inhibitors are presented. Possibilities of using sitagliptin in elderly patients were also considered. Finally, evidence-based studies demonstrating the obvious advantages of sitagliptin for the treatment of T2DM in the elderly and advanced aged population are discussed.

KEYWORDS: diabetes mellitus type 2; elderly; advanced age; geriatric syndromes; hypoglycemia; hypoglycemic therapy; DPP-4 inhibitors; sitagliptin

За последние годы в мире произошли значительные изменения в возрастной структуре населения, прогрессирующее постарение которого является наиболее характерным демографическим явлением современной эпохи. Сегодня во всем мире проживают 8,5\% людей (617 млн) в возрасте 65 лет и старше, а по прогнозам, к 2050 г. этот показатель увеличится почти до 17\% населения (1,6 млрд) [1].
В последние годы предлагались различные варианты классификации возрастных периодов в жизни людей, включая и поздний этап жизни, однако общепринятого определения пожилого возраста до сих пор нет. В соответствии с возрастной классификацией Всемирной организации здравоохранения люди в возрасте 60-74 лет считаются пожилыми, с 75 лет наступает период старости, а долгожителями являются лица старше 90 лет [2]. 
Таблица 1. Показатели распространенности сахарного диабета 2 типа в старших возрастных группах в РФ [4]

\begin{tabular}{lcc}
\hline Возраст, годы & Мужчины, \% & Женщины, \% \\
\hline $60-46$ & 19,0 & 17,1 \\
$65-69$ & 19,3 & 20,2 \\
$70-74$ & 10,2 & 11,9 \\
$75-79$ & 9,0 & 14,1 \\
$80-84$ & 5,5 & 9,5 \\
85 и более & 3,2 & 6,1 \\
\hline
\end{tabular}

По мере увеличения возраста значительно увеличивается распространенность сахарного диабета 2 типа (СД2), чему способствует и рост продолжительности жизни населения. В связи с этим заслуживают внимания вопросы ведения пациентов с СД2 не только пожилого, но и старческого возраста [3]. Показатели распространенности СД2 в РФ на 31.12.2017 г. также наиболее велики в старших возрастных группах (табл. 1) [4]. В частности, общее количество пациентов старше 65 лет, по данным Федерального регистра СД (ФРСД) на 31.12.2017 г., составило 2293 520, среди которых 2271500 - с СД2 (или $54,7 \%$ от всех пациентов с СД2), из них $76 \%$ женщин (1 735 000) [4].

\section{ОСОБЕННОСТИ СД2 У ПОЖИЛЫХ ПАЦИЕНТОВ}

С учетом увеличения доли пожилых людей, лечение СД2 у такой возрастной категории является одной из важных медико-социальных проблем. Сахароснижающая терапия особенно сложна в этой популяции из-за повышенного риска гипогликемии, наличия полиорганной патологии, которая оказывает значимое влияние на течение СД2. Пациенты с СД2 пожилого возраста чаще имеют такие сопутствующие сердечно-сосудистые заболевания, как артериальная гипертензия, нарушения сердечного ритма, ИБС, цереброваскулярная болезнь. При этом у пожилых пациентов с СД2 смертность в два раза выше, чем среди пожилых людей без диабета [5]. На фоне назначения терапии как СД2, так и коморбидной патологии формируется проблема полипрагмазии [6].

СД2 в пожилом возрасте ассоциирован не только с увеличением количества заболеваний, чаще хронического течения, но и с развитием ряда гериатрических синдромов, которые следует учитывать при назначении сахароснижающей терапии [6-10] (табл. 2).

У пациентов с СД2 старшей возрастной категории гораздо чаще, чем у пожилых лиц без этого заболевания, имеют место когнитивные нарушения. Обычно они выражаются быстрой утомляемостью, неадекватными эмоциональными реакциями, ухудшением памяти, внимания, более медленным усвоением новых навыков и др. На дальнейшее прогрессирование когнитивной дисфункции влияют длительность СД2, неудовлетворительный контроль гликемии, гипогликемии $[9,10]$. Важно подчеркнуть, что когнитивная дисфункция является фактором низкой приверженности к любой терапии больного (в том числе сахароснижающей), ухудшения гликемического контроля, что, безусловно, требует более простой схемы лечения заболевания. Рациональная, безопасная в отно- шении гипогликемий сахароснижающая терапия замедляет процесс развития когнитивной дисфункции $[6,7]$.

До 25-35\% больных СД2 в пожилом возрасте страдают эпизодами депрессии, что значительно выше, чем в общей популяции. Наличие депрессивных состояний ухудшает гликемический контроль, что обусловлено снижением их физической активности, увеличением массы тела, а также недостаточным выполнением врачебных рекомендаций $[6,10]$.

У людей пожилого и преклонного возраста (чаще женского пола) нередко имеет место недержание мочи (инконтиненция), оказывающее негативное влияние на качество жизни $[8,10]$. В своем исследовании Huyen T.V. с участием 322 пациентов с СД2 (средний возраст 74,8 8, 28 года) обнаружил высокую распространенность недержания мочи $(65,2 \%)$ [11]. Также анализ показал, что преклонный возраст, длительность СД2, уровень глюкозы натощак, гликированного гемоглобина $\left(\mathrm{HbA}_{1 c}\right)$, когнитивные нарушения и наличие полипрагмазии связаны с повышенным риском развития недержания мочи у пожилых больных СД2.

С возрастом увеличивается риск обезвоживания, чему способствуют уменьшение количества воды в организме на фоне старения, снижение порога восприятия жажды в гипоталамусе, изменения и болезни мочевыделительной системы $[12,13]$. Хроническая гипергликемия, полиурия дополнительно могут усугублять нарушения водного баланса у пожилых пациентов с СД2.

Старение организма сопровождается вегетативной дисрегуляцией: снижением чувствительности барорецепторов, а-адренергического вазоконстрикторного ответа при компенсаторной симпатической активации, тонуса блуждающего нерва, а также повышением уровня натрийуретического пептида и снижением активности ренин-ангиотензин-альдостероновой системы. Описанные механизмы способствуют развитию ортостатической гипотензии, которая является независимым предиктором смерти от всех причин и неблагоприятных сердечно-сосудистых событий [14]. Более высокий риск наличия ортостатической гипотензии у пациентов с СД2 по сравнению с общей популяцией обусловлен автономной кардиальной нейропатией.

Таблица 2. Основные гериатрические синдромы

\section{Когнитивные нарушения}

Дементные состояния (болезнь Альцгеймера, сенильный психоз)

\section{Саркопения}

Дегидратация, ортостатическая гипотензия

Снижение слуха, зрения

Головокружение

Падения, остеопороз, переломы

Синдром недостаточности питания

Нарушение сна

Недержание мочи

Нарушение передвижения

Старческая астения 
Пожилые пациенты с СД2 подвержены более высокому риску развития гипогликемий по сравнению с лицами более молодого возраста $[5-7,15]$. Хорошо известно, что возраст пациента сам по себе является важным фактором риска гипогликемии $[16,17]$. Согласно результатам исследований ACCORD и ADVANCE, на каждый дополнительный год жизни частота тяжелых гипогликемий увеличилась на 3 и 5\% соответственно [17]. Особенно высок риск гипогликемий у лиц старческого возраста. В частности, в крупном популяционном ретроспективном исследовании $(\mathrm{n}=20000)$ выявлено, что у пациентов старше 70 лет относительный риск (ОР) тяжелых гипогликемий увеличивается на $10 \%$ по сравнению с больными 65-69 лет, а у пациентов >75 лет и в возрасте 76-80 лет уже на 50\% и 80\% соответственно [17].

Гипогликемии в любом возрасте увеличивают риск кардиоваскулярной и общей смертности, но, конечно, особенно уязвимы пациенты пожилого и старческого возраста, для которых даже легкая или бессимптомная гипогликемия представляет серьезную опасность $[5,17,18]$. Гипогликемические эпизоды могут иметь катастрофические последствия не только для сердечно-сосудистой системы (острый инфаркт миокарда, инсульт, гипертонический криз, нарушение сердечного ритма); они часто сопровождаются падениями и их последствиями (переломы, травмы головы, субдуральные гематомы и др.), ухудшают когнитивную функцию, способствуют деменции $[19,20]$. Причин для высокого риска развития гипогликемии в пожилом возрасте немало. Со старением, как правило, снижаются аппетит и вкусовая чувствительность к пище, формируется синдром «быстрого насыщения», при котором уменьшается объем принимаемой пищи из-за повышенной чувствительности центра насыщения гипоталамуса [20, 21]. Кроме того, риск гипогликемии повышается в пожилом возрасте вследствие нарушения функции почек, печени, наличия синдрома мальабсорбции, а также в связи с нарушением распознавания гипогликемии (возрастное снижение активности симпато-адреналовой системы) [21, 22]. Как уже отмечалось, наличие ряда гериатрических синдромов также может способствовать высокому риску гипогликемии у пожилых пациентов с СД2 [23].

Наличие в пожилом возрасте нескольких заболеваний является объективной предпосылкой полипрагмазии [6, 9]. Сочетанное применение нескольких лекарственных препаратов может усиливать побочное действие некоторых из них. Так, салицилаты и другие нестероидные противовоспалительные препараты, которые широко используются в клинической практике, усиливают сахароснижающую активность препаратов сульфонилмочевины (ПСМ) и могут спровоцировать гипогликемию.

\section{ЛЕЧЕНИЕ}

Лечение СД2 у пожилых людей заслуживает отдельного обсуждения и требует тщательного рассмотрения сопутствующих гериатрических синдромов и состояний, которые увеличивают риск осложнений, включая тяжелую гипогликемию [24]. Однако, несмотря на опасность гипогликемии в пожилом возрасте, гликемический контроль является важным фактором предотвращения диабетиче- ских осложнений (часто летальных), продления жизни, а также улучшения качества жизни [5]. Известно, что риск развития макрососудистых осложнений у пожилых пациентов значительно выше, чем у молодого и среднего возраста с СД2 [25-27]. К сожалению, существует ограниченное количество исследований (субанализов), изучающих влияние сахароснижающей терапии на сердечно-сосудистые и другие осложнения, смертность в этой популяции пациентов [28]. В частности, даже в исследование UKPDS не были включены лица старше 65 лет.

Для сахароснижающих препаратов, применяемых у лиц пожилого и преклонного возраста, предъявляются особые требования: минимальный риск развития гипогликемии, сердечно-сосудистая безопасность, отсутствие нефро-, гепатотоксичности, простой, удобный режим приема; побочные эффекты терапии должны быть незначительными [6, 7, 23, 24]. Следует помнить, что у пожилых больных значительно чаще встречается хроническая болезнь почек (ХБП), что ограничивает выбор сахароснижающего препарата. Также необходимо учитывать сопутствующие заболевания и их лечение [23].

Рекомендации РАЭ от 2019 г. [29] предлагают подход для индивидуализированного выбора целей терапии по $\mathrm{HbA}_{1 c^{\prime}}$ основанный на возрасте пациента и клинических характеристиках пациентов: наличии атеросклеротических сердечно-сосудистых заболеваний (АССЗ)/риска тяжелой гипогликемии (табл. 3). Для определения индивидуального уровня $\mathrm{HbA}_{1 с}$ у пациентов пожилого возраста эти принципы предполагают их разделение на две категории: функционально независимые лица и функционально зависимые лица. Уровень $\mathrm{HbA}_{1 c}<7,5 \%$ рекомендован для функционально независимых пациентов пожилого возраста в случае отсутствия у них АСС3/риска тяжелой гипогликемии; при наличии АСС3/риска тяжелой гипогликемии следует стремиться к достижению уровня $\mathrm{HbA}_{1 c}<8,0 \%$. Для функционально зависимых пожилых пациентов, не имеющих старческой астении и/или деменции, рекомендован целевой уровень $\mathrm{HbA}_{1 с}<8,0 \%$; для тех, у кого есть старческая астения и/или деменция - <8,5\%. Вместе с тем у пожилых пациентов на завершающем этапе жизни цель лечения должна заключаться не в достижении конкретной цели $\mathrm{HbA}_{1 c^{\prime}}$ а в минимизации симптомов гипергликемии, также необходимо избегать гипогликемий.

Низкий риск гипогликемии, эффективность, положительное влияние на сердечно-сосудистые заболевания, низкая стоимость делают метформин привлекательным выбором для пожилых пациентов [30]. Факторами, которые ограничивают применение препарата в этой популяции пациентов, являются желудочно-кишечные побочные эффекты. Однако, начиная лечение с небольшой дозы 500 мг/сут, можно минимизировать нежелательные эффекты метформина со стороны кишечного тракта, медленно увеличивая дозу препарата в течение нескольких недель. Использование метформина ограничивается нарушением функции почек, он противопоказан при скорости клубочковой фильтрации (СКФ) <30 мл/мин/1,73 м². Также следует помнить, что суточная доза метформина не должна превышать 1000 мг в случае СКФ 30-44 мл/мин/1,73 м² [29]. Состояния, сопровождающиеся гипоксией (острая недостаточность мозгового кровообращения, сердечная, легочная недо- 
Таблица 3. Алгоритм индивидуализированного выбора целей терапии по уровню гликированного гемоглобина

\begin{tabular}{|c|c|c|c|c|c|c|}
\hline \multirow[t]{2}{*}{ Категории пациентов } & & & \multicolumn{4}{|c|}{ Пожилой возраст } \\
\hline & \multirow[b]{2}{*}{$\begin{array}{c}\text { Молодой } \\
\text { возраст }\end{array}$} & \multirow[b]{2}{*}{$\begin{array}{l}\text { Средний } \\
\text { возраст }\end{array}$} & \multicolumn{4}{|c|}{ Функционально зависимые } \\
\hline $\begin{array}{c}\text { Клинические } \\
\text { характеристики/ } \\
\text { риски }\end{array}$ & & & $\begin{array}{c}\text { Функционально } \\
\text { независимые }\end{array}$ & $\begin{array}{c}\text { Без } \\
\text { старческой } \\
\text { астении } \\
\text { и/или } \\
\text { деменции }\end{array}$ & $\begin{array}{c}\text { Старческая } \\
\text { астения } \\
\text { и/или } \\
\text { деменция }\end{array}$ & $\begin{array}{c}\text { Завершающий } \\
\text { этап жизни }\end{array}$ \\
\hline
\end{tabular}

Нет атеросклеротических

сердечно-сосудистых

заболеваний ${ }^{* *} /$ риска

$<6,5 \% \quad<7,0 \% \quad<7,5 \%$

тяжелой гипогликемии ${ }^{* * *}$

Есть атеросклеротические

сердечно-сосудистые

заболевания/риск

тяжелой гипогликемии

При низкой ожидаемой продолжительности жизни (<5 лет) цели лечения могут быть менее строгими.

Примечания: *Данные целевые значения не относятся к детям, подросткам и беременным женщинам; ** нормальный уровень в соответствии со стандартами DCСТ: до 6\%; *** ИБС (стенокардия, инфаркт миокарда в анамнезе, шунтирование/стентирование коронарных артерий); нарушение мозгового кровообращения в анамнезе; заболевания артерий нижних конечностей (с симптоматикой); ****основными критериями риска тяжелой гипогликемии являются: наличие тяжелой гипогликемии в анамнезе, бессимптомная гипогликемия, большая продолжительность СД, хроническая болезнь (ХБП) С 3-5, деменция.

статочность, инфаркт миокарда, анемия и др.), печеночная недостаточность, хронический алкоголизм, острые состояния, которые могут нарушить функцию почек (дегидратация, острая инфекция, шок), ацидоз любого генеза являются противопоказаниями для применения метформина [29-31]. Следует помнить, что у некоторых больных пожилого возраста длительное лечение метформином ассоциировано со снижением сывороточных концентраций витамина $\mathrm{B}_{12}$, что потенциально может приводить к усугублению имеющихся когнитивных нарушений [32].

До разработки сахароснижающих препаратов с низким риском гипогликемий, при непереносимости или наличии противопоказаний для назначения метформина альтернативой, как правило, было назначение ПСМ. Также их обычно использовали для интенсификации сахароснижающей терапии в случае неэффективности монотерапии метформином. Как уже отмечалось, крайне опасным побочным эффектом этой группы сахароснижающих препаратов для больных старшей возрастной категории является развитие гипогликемии. Вместе с тем показано, что риск гипогликемии зависит от продолжительности действия и особенностей метаболизма ПСМ [33].

Ингибиторы натрий-глюкозного котрнаспортера 2, блокирующие реабсорбцию глюкозы в почках и увеличивающие глюкозурию, обладают высокой эффективностью и низким риском развития гипогликемических состояний. Согласно рекомендациям, эти препараты в пожилом возрасте следует применять с осторожностью и избегать сочетания с диуретиками [29, 34]. Необходим тщательный контроль лечения с учетом риска развития дегидратации и ортостатической гипотонии, а также особая осторожность должна быть у пожилых пациентов с повышенным риском мочеполовых инфекций и недержанием мочи.

Концепция сниженного «эффекта инкретинов» при СД2 послужила основанием для внедрения в клиниче- скую практику ингибиторов дипептидилпептидазы-4 (иДПП-4) [35, 36]. С момента появления в клинической практике иДПП-4 внимание к ним не ослабевает. Наличие у иДПП-4 предсказуемого сахароснижающего эффекта без рисков гипогликемий, хорошей переносимости, благоприятного сердечно-сосудистого потенциала позволяет широко использовать их у пациентов с СД2 пожилого и преклонного возраста [37, 38].

В соответствии с Российскими Алгоритмами специализированной медицинской помощи больным СД выбор терапии базируется на отличии исходного показателя $\mathrm{HbA}_{1 с}$ от индивидуального целевого уровня. Если $\mathrm{HbA}_{1 с}$ превышает индивидуальный целевой уровень менее чем на $1 \%$, то рекомендована монотерапия, если на 1,0-2,5\%, то следует использовать комбинацию препаратов. Выбор пероральных сахароснижающих препаратов (ПССП) производится в зависимости от доминирующей клинической проблемы. При этом у пациентов пожилого возраста, помимо метформина, предпочтение имеют препараты из группы иДПП-4 как обладающие наиболее благоприятным профилем безопасности, в том числе в отношении развития гипогликемии и возможности применения при любой стадии ХБП [29].

Механизм действия иДПП-4 заключается в подавлении активности фермента ДПП-4, благодаря чему замедляется разрушение глюкагоноподобного пептида-1 (ГПП-1) и глюкозозависимого инсулинотропного полипептида (ГИП), пролонгируется взаимодействие этих гормонов со специфическими рецепторами и действие на уровне органов-мишеней (рис. 1) [36]. Для клинической практики важно, что иДПП-4 обладают глюкозозависимым механизмом действия, благодаря чему их прием ассоциирован с низким риском гипогликемии. Это является неоспоримым преимуществом для лиц пожилого возраста, пациентов с макрососудистой патологией, пациентов с высоким риском гипогликемии (например, при ХБП). Дополнительным преимуществом иДПП-4 яв- 


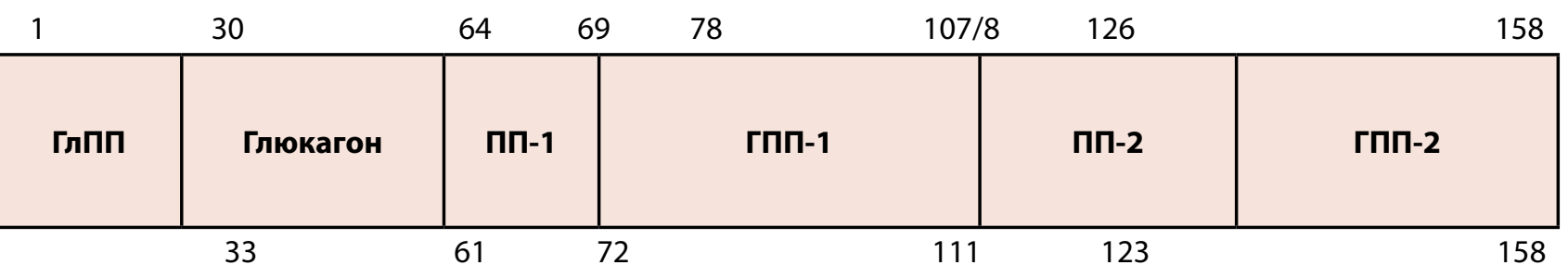

ГПП-1 (7-37)

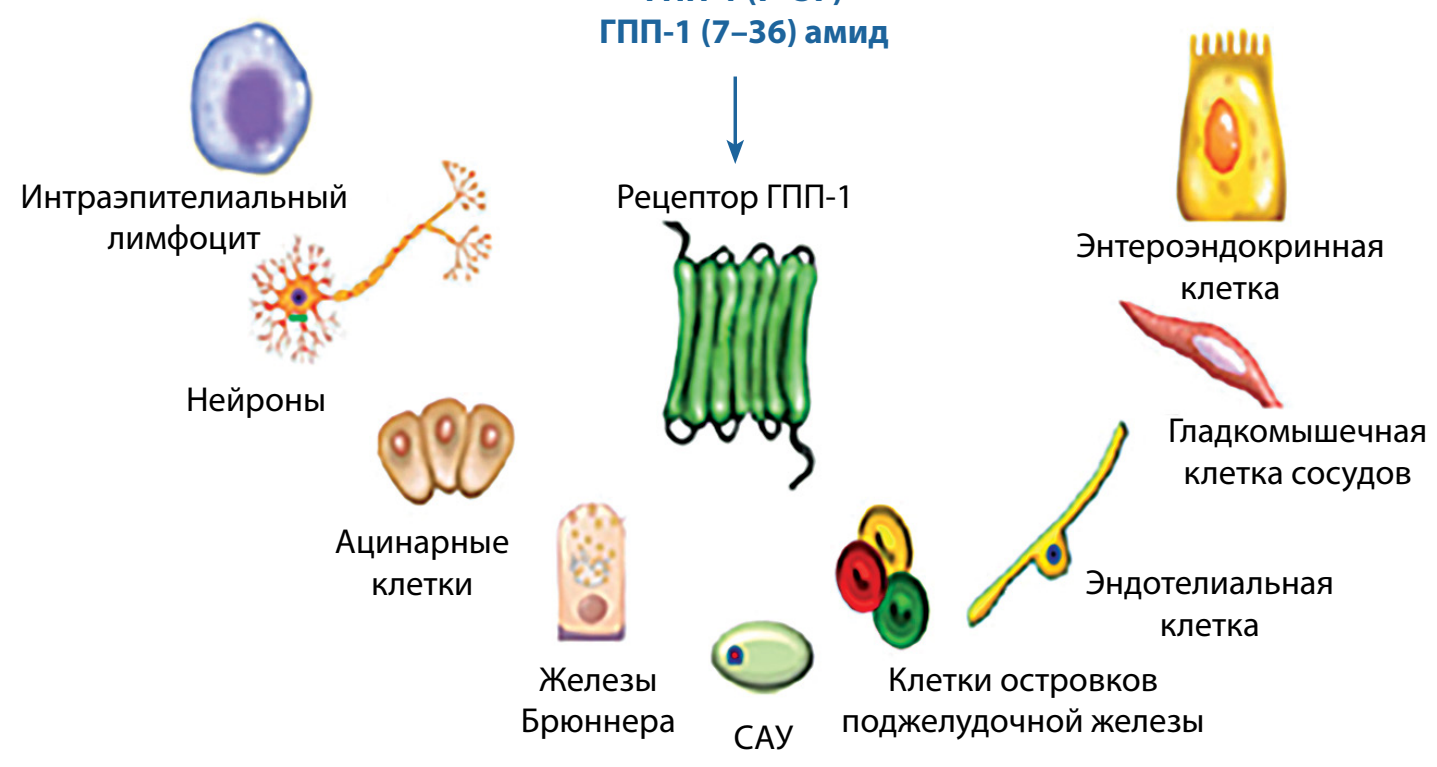

Рис. 1. Происхождение глюкагоноподобного пептида-1, основные клетки и органы, имеющие рецепторы глюкагоноподобного пептида-1 (цит. по Drucker D. J. [36]) с изменениями).

Примечание. ГлПП - глинцептин-связанный панкреатический полипептид; ГПП-2 - глюкагоноподобный пептид; ПП-1 и ПП-2 - промежуточные пептиды 1 и 2; САУ - синоатриальный узел.

ляется их потенциальный протективный эффект в отношении $\beta$-клеток.

Все еще остается открытым вопрос о возможных плейотропных эффектах иДПП-4, независимых от воздействия на гликемию, которые могут иметь определенное клиническое значение для предотвращения развития хронических осложнений СД2 и воплотиться в улучшение прогноза заболевания [36, 39]. Ингибирование ГПП-1 и ГИП посредством ДПП-4 является не единственным процессом, где задействован этот фермент. К его субстратам относятся и иные молекулы, в том числе нейропептиды, хемокины, вазоактивные пептиды, цитокины (нейропептид Y, пептид Y, стромальный клеточный фактор 1a/SDF-1a и 1ß/CXCL12, хемотаксический белок гранулоцитов-2/CXCL6, макрофагальный хемокин/ CCL22/MDC и др.), принимающие участие в различных биологических процессах, среди которых особенно важны воспалительные, иммунные реакции, регенерация, чувствительность тканей к инсулину.

Опосредованное влияние глиптинов на метаболизм различных пептидов и, соответственно, модуляция их активности, по всей видимости, лежат в основе внегликемических эффектов данного класса сахароснижающих препаратов. В частности, блокирование активности ДПП4 повышает уровень стромального клеточного фактора 1 а и, соответственно, пролонгирует действие этого хемокина, что способствует привлечению мезенхимальных стволовых клеток и клеток-предшественниц к зонам повреждения в сердечно-сосудистой системе, с последующей регенерацией тканей и восстановлением кровотока в поврежденных тканях $[36,39,40]$.
Наряду с контролем гликемии, обсуждаемые эффекты в долгосрочном плане могут оказывать положительное влияние на многие кардиопротективные механизмы [39]. Так, есть данные о способности иДПП-4 улучшать эндотелиальную функцию, увеличивать количество и активность эндотелиальных прогениторных клеток, снижать концентрации провоспалительных маркеров, выраженность окислительного стресса, уменьшать выраженность альбуминурии [40].

\section{Преимущества применения ингибиторов ДПП-4}

у пожилых пациентов с СД2

При лечении пожилых больных СД2 перед клиницистами встает вопрос выбора эффективного, но и наиболее безопасного в отношении гипогликемии препарата. С появлением группы иДПП-4 существенно расширились возможности терапии СД2, что особенно касается пациентов пожилого возраста. В нескольких клинических исследованиях (КИ) были непосредственно изучены безопасность и эффективность иДПП-4 у пожилых пациентов с СД2 с участием лиц старше 75 лет с различными сопутствующими заболеваниями $[41,42]$. Эффективность иДПП-4 была практически равнозначной при использовании в качестве монотерапии или в комбинации с метформином.

Первый высокоселективный иДПП-4 ситаглиптин появился в клинической практике в 2006 г.; позже появились другие представители класса иДПП-4. Результаты post hoc-анализа совокупности рандомизированных КИ, а также проспективных и ретроспективных обсервационных исследований свидетельствуют о высокой эффек- 
тивности, благоприятном профиле безопасности и хорошей переносимости ситаглиптина у пациентов с СД2 пожилого возраста [41-43].

Нельзя обойти вниманием результаты ретроспективного обсервационного исследования с участием 831 пациента с СД2, в котором ситаглиптин применялся в виде монотерапии или в дополнение к другой сахароснижающей терапии (ПСМ, тиазолидиндионы, ингибиторы а-глюкозидазы), период наблюдения составил 2 года [42]. Сахароснижающие средства назначались на усмотрение специалиста в соответствии с существующей практикой. Участники исследования в зависимости от возраста были разделены на три группы: $<65$ лет (54,8 7,8 года),

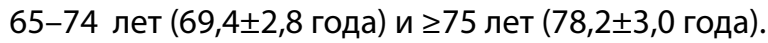

Исходно без терапии были 18,4\% пациентов, а соответственно 31,5\% и 50,1\% получали моно- и комбинированную сахароснижающую терапию. В частности, большинство ( $\mathrm{n}=529)$ получали ПСМ (61,9\% - в группе <65 лет, 67,4\% - в группе 65-74 лет и 61,1\% - в группе старше $\geq 75$ лет) и метформин (56,7\% - в группе <65 лет, 50,0\% - в группе 65-74 лет и 34,9\% - в группе старше $\geq 75$ лет). Сахароснижающая эффективность, переносимость и безопасность ситаглиптина у больных пожилого и старческого возраста не отличались от лиц среднего возраста. В группе пациентов моложе 65 лет при назначении ситаглиптина уровень $\mathrm{HbA}_{1 с}$ достоверно снизился $(\mathrm{p}<0,05)$ с $8,1 \pm 1,2 \%$

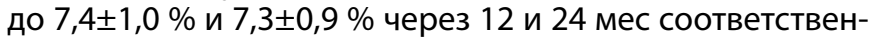
но. Существенное снижение $(\mathrm{p}<0,05)$ уровня $\mathrm{HbA}_{1 c}$ на-

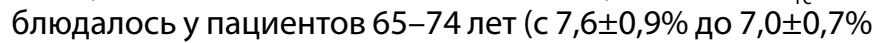
и $7,0 \pm 0,7 \%$ соответственно) и у пациентов $\geq 75$ лет

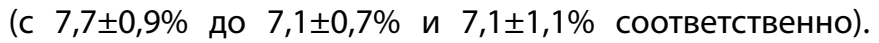
Во всех возрастных группах больных СД2 ситаглиптин не вызывал прибавки массы тела.

Гипогликемии были отмечены только при комбинации ситаглиптина с ПСМ (58 человек). Детальный анализ продемонстрировал сопоставимую динамику $\mathrm{HbA}_{1 c}$ во всех возрастных группах у пациентов, получавших ситаглиптин в комбинации с ПСМ (529 из 831 человека). Частота гипогликемий в группе <65 лет составила 5,73/100 человеко-лет, в группе 65-74 лет - 5,79/100 че- ловеко-лет и в группе старше $\geq 75$ лет - 3,79/100 человеко-лет (рис. 2).

Результаты этого исследования свидетельствуют о хорошей эффективности и высокой безопасности длительного применения ситаглиптина у наиболее уязвимой категории пациентов - лиц пожилого и старческого возраста.

В 2018 г. исследовательская группа по гипогликемиям Fukuda М. опубликовала результаты открытого многоцентрового проспективного исследования (Impact of Sitagliptin on Diabetes Mellitus in Japanese elderly patients) с участием 5130 пациентов с СД2 в возрасте $\geq 65$ и <90 лет с неудовлетворительным контролем на проводимой сахароснижающей терапии, которым впервые был назначен ситаглиптин [43]. Средний возраст участников в исследовании составил 73,8 26,1 года, по возрастным категориям пациенты распределялись следующим образом: 57,7\% - в возрасте 65-74 лет, 36,3\% - в возрасте 75-84 лет и 6,0\% - в возрасте 85+. Через 52 нед наблюдения уровень $\mathrm{HbA}_{1 с}$ снизился на $0,7 \pm 1,1 \%(p<0,0010)$. При этом во всех возрастных группах отмечено схожее снижение $\mathrm{HbA}_{1 c}$ без прироста частоты гипогликемий. При комбинации ситаглиптина с препаратами, которые вызывают гипогликемию, - с инсулином (ОШ 17,75, p<0,001) и ПСМ (ОШ 2,22, p<0,001), частота гипогликемий была выше.

Эта работа еще раз подтвердила возможность эффективного и безопасного применения ситаглиптина у лиц пожилого и старческого возраста. На практике, чтобы избежать гипогликемии при комбинации ситаглиптина с ПСМ или инсулином, традиционно рекомендуемую дозу ПСМ или инсулина целесообразно уменьшить для снижения риска развития гипогликемии.

У пожилых пациентов с СД2 существует высокий риск развития осложнений заболеваний, обусловленных атеросклерозом, ассоциированный с возрастом [24]. Нельзя не отметить преимущества ситаглиптина как препарата, обеспечивающего не только эффективный, но и безопасный гликемический контроль, что особенно важно для лиц пожилого возраста. Результаты исследования TECOS (Trial Evaluating Cardiovascular Outcomes with Sitagliptin) четко показали, что ситаглиптин не увеличивает риск

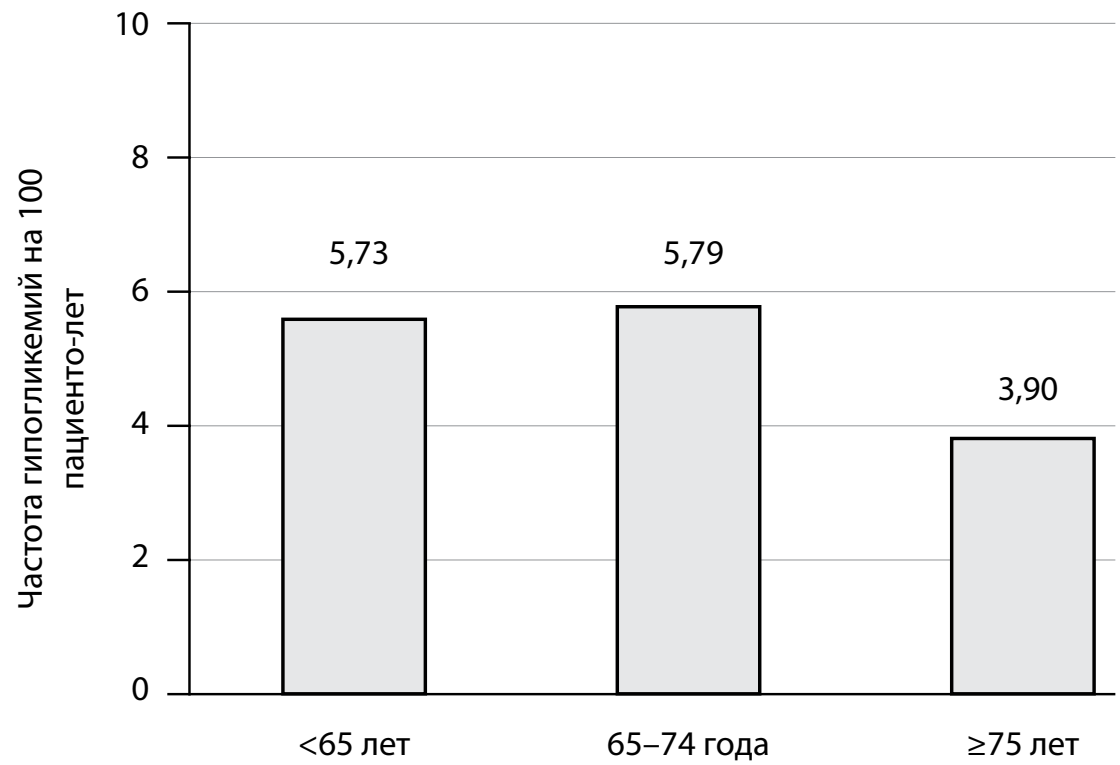

Рис. 2. Частота гипогликемий в различных возрастных категориях пациентов с сахарным диабетом 2 типа, получавших ситаглиптин в добавление к препаратам сульфонилмочевины в течение двухлетнего периода наблюдения [43]. 
основных неблагоприятных сердечно-сосудистых событий (смерти от сердечно-сосудистого заболевания, нефатального инфаркта миокарда и инсульта, нестабильной стенокардии, требующей госпитализации), а также госпитализаций по поводу сердечной недостаточности [44]. Дополнительный анализ данных TECOS, в котором группы были стандартизированы по наличию СН в начале исследования, подтвердил безопасность ситаглиптина в отношении сердечной недостаточности. Частота госпитализаций по поводу сердечной недостаточности осталась одинаковой в обеих группах (ОР 1,00; 95\% ДИ 0,83-1,20; $p=0,98)$ [45].

B работе Arnets L. и соавт. было показано, что терапия ситаглиптином у пациентов с СД2 и острым коронарным синдромом сопровождалась снижением риска повторного инфаркта, отека легких и острой почечной недостаточности [46]. Также в эксперименте на животных моделях продемонстрировано уменьшение проявлений диабетической кардиомиопатии [47].

Молекулярные механизмы потенциальных кардиопротективных эффектов ситаглиптина активно изучаются в эксперименте. Для ситаглиптина характерно сочетание противовоспалительного (супрессия сигнальных механизмов провоспалительных цитокинов, снижение уровня маркеров воспаления ICAM-1, VCAM-1, PAI-1), антиатеросклеротического, антиапоптотического и антиоксидантного (снижение активных форм кислорода) эффектов, а также улучшение функции эндотелия (увеличение экспрессии синтазы оксида азота), снижение адгезии моноцитов. Дополнительно к сказанному выявлено подавление процессов активации, пролиферации и миграции сосудистых гладкомышечных клеток и увеличение активности каспазы-3 [48-50]. Перспективным является дальнейшее более углубленное изучение плейотропных эффектов ситаглиптина и реализации их на практике.

Вместе с тем оценка и анализ реальной клинической практики лечения СД2 позволяют узнать приоритеты врачей в выборе тактики для пациентов пожилого и старческого возраста с учетом разнообразия сахароснижающих средств. На основании данных, полученных с помощью электронной базы США (MarketScan, Medicare Supplemental Database), инициировано исследование с целью получения информации о рутинной практике ведения больных СД2 пожилого возраста на старте сахароснижающей терапии [51]. Критериями включения пациентов было подтверждение диагноза СД2, возраст $>65$ лет, наличие электронной карты пациентов в базе данных не менее 1 года до начала назначения сахароснижающих препаратов (в том числе и ситаглиптина). В исследование не включали пациентов, получающих инъекционную сахароснижающую терапию. Пациенты ( $n=155$ 388) были разделены на три категории в зависимости от лечения: начало монотерапии, переход к двойной и к тройной комбинированной терапии.

Оценка структуры сахароснижающей терапии, назначенной впервые больным СД2, показала, что большинству $(52,1 \%, n=80$ 929) была назначена монотерапия ситаглиптином ( $\mathrm{n}=3234)$ или другими сахароснижающими препаратами (не иДПП-4) ( $n=77$ 695). Анализ сахароснижающей терапии у больных, ранее получавших такую терапию, показал, что 36,8\% ( $n=57$ 206) пациентов была рекомендована двойная сахароснижающая терапия, из них ситаглиптин был назначен 7652 пациентам. Наконец, тройная сахароснижающая терапия была назначена 11,1\% (n=17 253), из них ситаглиптин - 4429 пациентам.

В рамках каждой категории сахароснижающей терапии было проведено сравнение ситаглиптина с другими сахароснижающими препаратами у пациентов разных возрастных групп: 65-74 года, 75-84 года и 85+. Среди исходных характеристик каждой группы детальному анализу были подвержены сопутствующие заболевания и состояния (аритмия, застойная сердечная недостаточность, инсульт/транзиторная ишемическая болезнь, когнитивные дисфункции, переломы, потеря слуха, гипертензия, инфаркт миокарда, нейропатия, заболевание периферических сосудов, протеинурия, почечная недостаточность, ретинопатия, заболевания глаз, гипогликемия), зарегистрированные в течение 12 мес до даты индекса (определяемой как дата начала/усиления сахароснижающей терапии).

В результате были выявлены приоритеты врачей в выборе ПССП у пожилых пациентов: ситаглиптин без опасений назначался пожилым пациентам, включая лиц преклонного возраста, а также тем, кто имел тяжелую сопутствующую патологию в анамнезе (аритмии, застойная сердечная недостаточность, почечная недостаточность, инсульт).

Это исследование с большой выборкой пациентов позволило получить ценные данные о реальной клинической практике, сложившейся в области лечения пациента с СД2 пожилого возраста.

Определенный интерес представляют результаты опубликованного в этом году наблюдательного открытого исследования с участием 115 пациентов пожилого возраста, в котором оценивали не только эффективность иДПП-4, но и удовлетворенность пациентов лечением, используя «Опросник удовлетворенности лечением при диабете» (Diabetes Treatment Satisfaction Questionnaire, DTSQ) [52]. В этом моноцентровом кросс-секционном сравнительном обсервационном исследовании пожилые больные СД2 (которые принимали сахароснижающие препараты не менее 3 мес до включения в исследование) были разделены в две группы терапии. Группа 1

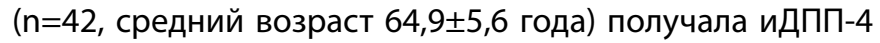
(ситаглиптин, n=15, вилдаглиптин, n=14, тенеглиптин, $\mathrm{n}=13)$ в виде монотерапии или в составе комбинированной терапии (метформин, ПСМ, пиоглитазон, инсулин),

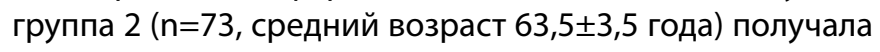
другие сахароснижающие препараты (не идПП-4) в виде монотерапии (метформин, ПСМ, пиоглитазон, инсулин) или в составе комбинированной терапии.

Через 2 мес терапии между группами была получена статистически значимая разница по уровню $\mathrm{HbA}_{1 с}$

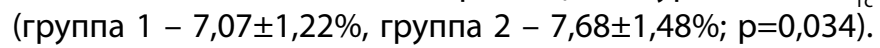
Разницы по $\mathrm{HbA}_{1 c}$ между различными иДПП-4 не было отмечено. Кроме того, достоверно больше пациентов группы 1 достигли $\mathrm{HbA}_{1 с}<7 \%$ по сравнению с группой 2 (62\% и 33\% соответственно; $p=0,002 ; 95 \%$ ДИ 11,8-48, 1\%). Важно отметить, что, согласно опроснику DTSQ, отмечена статистически значимая положительная динамика удовлетворенности лечением в группе 1.

Серьезную опасность для больных СД2 пожилого и старческого возраста представляет ХБП, поскольку с возрастом ее распространенность резко возрастает. 
Известно, что каждый четвертый в возрасте 65-74 лет и более половины лиц в возрасте старше 75-77 лет имеют 3-5 стадию ХБП [53].

Нарушение функции почек является дополнительным фактором, предрасполагающим к частым гипогликемиям, увеличивает риск неблагоприятных лекарственных взаимодействий, ограничивает в выборе препаратов из-за противопоказания к терапии, что значительно усложняет лечение любого заболевания. По мере снижения СКФ неуклонно растет число коморбидных состояний, и данная взаимосвязь особенно ощутима именно у больных СД2 старших возрастных групп. Наличие ХБП значительно ухудшает прогноз жизни у этих пациентов, определяет высокую вероятность фатальных сердечно-сосудистых осложнений. Кроме того, альбуминурия и снижение расчетной СКФ выступают независимыми предикторами дисфункции лобной доли головного мозга в пожилом возрасте [54].

Особенности фармакодинамики (80\% экскретируется почками в неизмененном виде) позволяют безопасно применять ситаглиптин при наличии почечной недостаточности, при СКФ >45 мл/мин нет необходимости изменения его дозы [55].

Эффективность и безопасность ситаглиптина у больных СД2 с различными стадиями ХБП, с терминальной почечной недостаточностью на диализе, в том числе и пожилого возраста, продемонстрирована в клинических исследованиях. Наряду с улучшением гликемического контроля ситаглиптин снижает уровень альбуминурии, степень фиброза, уровень цистатина, провоспалительных маркеров [55]. Существуют экспериментальные данные, что ситаглиптин ингибирует активность сигнального пути TGF- $\beta 1 / S m a d 3$, что сопровождается уменьшением выработки коллагена IV типа, уровня фибронектина [56], указывает на нефропротективный потенциал препарата. Однако подобные механизмы иДПП-4 требуют уточнения.

Улучшение контроля гликемии в совокупности с перечисленными негликемическими эффектами ситаглиптина может иметь клиническое значение для предотвращения прогрессирования диабетической нефропатии.

Кроме того, следует отметить, что ситаглиптин первично выводится почками, как следствие, не требуется коррекции дозы препарата у пациентов с нарушениями функции печени легкой и средней степени тяжести [57].

\section{Ситаглиптин и гериатрические синдромы}

С увеличением числа пожилых людей с СД2 число пациентов с когнитивной дисфункцией также возрастает $[25,58]$. По сравнению с общей популяцией у лиц, страдающих СД2, риск деменции возрастает не менее чем в 1,5 раза [54]. Имеются данные экспериментальных и клинических исследований, что некоторые иДПП-4, особенно ситаглиптин, могут оказывать положительное влияние на когнитивные функции [58].

В этом плане представляют интерес данные недавно опубликованного проспективного обсервационного исследования Isik A.T. и соавт. длительностью 6 мес с участием 253 пожилых пациентов с СД2 (из них 52 с сопутствующей болезнью Альцгеймера) [59]. В зависимости от фармакотерапии пациенты были разделены на 2 группы: группа, получавшая ситаглиптин, и группа, получавшая другие сахароснижающие препараты. В ка- честве скринингового инструмента оценки нарушения когнитивных функций шкалы применялась малая шкала определения ментального статуса - MMSE (Mini-Mental State Examination). Анализ показал, что назначение ситаглиптина в течение 6 мес достоверно улучшило когнитивные функции у пациентов с СД2 (p=0,034). У пациентов без сопутствующей болезни Альцгеймера в конце периода наблюдения на фоне терапии ситаглиптином или инсулином отмечены лучшие результаты по шкале MMSE по сравнению с пациентами, получавшими монотерапию метформином ( $p=0,024)$. На фоне применения ситаглиптина в подгруппе пациентов с СД2 и болезнью Альцгеймера также определено статистически значимое улучшение когнитивных функций. Аналогично к концу наблюдения межгрупповые различия (группа ситаглиптина и группа пациентов, получающих метформин) оказались статистически значимы. Авторы пришли к выводу о том, что терапия ситаглиптином может приводить к улучшению когнитивных функций у пожилых пациентов с СД2, как страдающих, так и не страдающих болезнью Альцгеймера.

Механизмы потенциального влияния ситаглиптина на головной мозг активно изучаются и могут быть связаны не только с улучшением гликемического контроля. Дополнительные нейропротективные свойства ситаглиптина, вероятно, опосредуются его антиоксидантными, противовоспалительными и антиапоптотическими механизмами действия $[55,60]$. В эксперименте на мышиной модели применение ситаглиптина значительно сокращало количество повреждений и выраженность воспалительных процессов в веществе головного мозга, уменьшало уровни провоспалительных маркеров (фактора некроза опухолей-а, интерлейкина (ИЛ) 6, ИЛ-17, CD163) и повышало уровни противовоспалительных маркеров (ИЛ-10, трансформирующего фактора роста- $\beta$ ). Показано, что ситаглиптин уменьшает количество отложений депозитов $\beta$-амилоида в структурах мозга мышей, что, по-видимому, опосредовано через SDF-1a (субстрат для ДПП-4), также препарат стимулирует нейрогенез и уменьшает окислительный стресс в гиппокампе грызунов. Антиоксидантные и антиапоптотические эффекты ситаглиптина также реализуются путем изменения уровня глутамата и глутатиона в области гиппокампа [60].

\section{ЗАКЛЮЧЕНИЕ}

В проблеме лечения пациентов с СД2 в пожилом возрасте за последние годы произошли существенные изменения; современные знания о патогенетических механизмах СД2 позволили предложить новые методы лечения. У пожилых больных, в том числе с коморбидной патологией, при лечении СД2 важную роль играет терапия иДПП-4. Ситаглиптин - хорошо изученный и безопасный сахароснижающий препарат, с доказанным низким риском гипогликемий, с благоприятным профилем переносимости, позволяющий улучшить прогноз заболевания.

\section{ДОПОЛНИТЕЛЬНАЯ ИНФОРМАЦИЯ}

Автор декларирует отсутствие конфликтов интересов, связанных с публикацией настоящей статьи. Поисково-аналитическая работа и подготовка статьи проведена на личные средства автора. 


\section{СПИСОК ЛИТЕРАТУРЫ | REFERENCES}

1. World's older population grows dramatically [Internet]. An Aging World National Institute on Aging; 2016 [cited 2016 March 28]. Available from: https://www.nia.nih.gov/news/worlds-olderpopulation-grows-dramatically/

2. Всемирная организация здравоохранения. Старение и жизненный цикл [интернет]. ВОЗ, 2015 [доступ от 30.09.2015]. [World Health Organization. Stareniye i zhiznennyy tsikl. WHO; 2015 (In Russ).] Доступно по: https://www.who.int/ageing/ru/

3. Yakaryllmaz FD, Öztürk ZA. Treatment of type 2 diabetes mellitus in the elderly. World J Diabetes. 2017;8(6):278-285. doi: https://doi.org/10.4239/wjd.v8.i6.278

4. Дедов И.И., Шестакова М.В., Викулова О.К., и др. Сахарный диабет в Российской Федерации: распространенность, заболеваемость, смертность, параметры углеводного обмена и структура сахароснижающей терапии по данным федерального регистра сахарного диабета, статус 2017 г. // Сахарный диабет. — 2018. T. 21. — №3. - C. 144-159. [Dedov II, Shestakova MV, Vikulova OK, et al. Diabetes mellitus in Russian Federation: prevalence, morbidity, mortality, parameters of glycaemic control and structure of glucose lowering therapy according to the Federal Diabetes Register, status 2017. Diabetes mellitus. 2018; 21(3):144-159. (In Russ).] doi: https://doi.org/10.14341/DM9686

5. Sinclair AJ, Robert IM, Croxson SC. Mortality in older people with diabetes mellitus. Diabet Med. 1997:14(8):639-647. doi: https:// doi.org/10.1002/(SICI)1096-9136(199708)14:8<639::AIDDIA433>3.0.CO:2-C

6. Yakaryılmaz FD, Öztürk ZA. Treatment of type 2 diabetes mellitus in the elderly. World J Diabetes. 2017:8(6):278-285. doi: https://doi.org/10.4239/wjd.v8.66.278

7. Sinclair A, Morley JE, Rodriguez-Manas L, et al. Diabetes mellitus in older people: position statement on behalf of the International Association of Gerontology and Geriatrics (IAGG), the European Diabetes Working Party for Older People (EDWPOP), and the International Task Force of Experts in Diabetes. J Am Med Dir Assoc. 2012;13(6):497-502. doi: https://doi.org/10.1016/j.jamda.2012.04.012

8. Чукаева И.И., Ларина В.Н. Возраст-ассоциированные состояния (гериатрические синдромы) в практике врача-терапевта поликлиник // Лечебное дело.- 2017. — №1. - С. 1-15 [Chukaeva II, Larina VN. Geriatric syndromes in a primary care setting. Lechebnoye delo. 2017;(1):1-15. (In Russ).]

9. Мкртумян А.М., Бирюкова Е.В. Особенности сахарного диабета в пожилом возрасте и принципы терапии // Сахарный диабет. — 2005. — №4. — C. 14-21. [Mkrtumyan AM, Biryukova EV. Osobennosti sakharnogo diabeta v pozhilom vozraste i printsipy terapii. Diabetes mellitus. 2005;(4):14-21. (In Russ).]

10. Delancey JO, Ashton-Miller JA. Pathophysiology of adult urinary incontinence. Gastroenterology. 2004;126(1 Suppl 1):S23-32. doi: https://doi.org/10.1053/j.gastro.2003.10.080.

11. Huyen T. Association between diabetes mellitus and urinary incontinence in elderly patients. Diabetes. 2018;67(Suppl 1):1481. doi: https://doi.org/10.2337/db18-1481-p

12. Cowen LE, Hodak SP, Verbalis JG. Age-associated abnormalities of water homeostasis. Endocrinol Metab Clin North Am. 2013;42(2):349-370. doi: https://doi.org/10.1016/j.ecl.2013.02.005

13. Beguma MN, Johnson CS. A review of the literature on dehydration in the institutionalized elderly. e-SPEN, Eur J Clin Nutr Metab. 2010;5(1):e47-e53. doi: https://doi.org/10.1016/j.eclnm.2009.10.007

14. Gupta V, Lipsitz LA. Orthostatic hypotension in the elderly: diagnosis and treatment. Am J Med. 2007;120(10):841-847. doi: https://doi.org/10.1016/j.amjmed.2007.02.023

15. Abdelhafiz AH, Rodríguez-Mañas L, Morley JE, Sinclair AJ. Hypoglycemia in older people - a less well recognized risk factor for frailty. Aging Dis. 2015;6(2):156-167. doi: https://doi.org/10.14336/AD.2014.0330

16. Miller ME, Bonds DE, Gerstein $\mathrm{HC}$, et al. The effects of baseline characteristics, glycaemia treatment approach, and glycated haemoglobin concentration on the risk of severe hypoglycaemia: post hoc epidemiological analysis of the ACCORD study. BMJ. 2010;340:b5444. doi: https://doi.org/10.1136/bmj.b5444

17. Shorr RI. Incidence and risk factors for serious hypoglycemia in older persons using insulin or sulfonylureas. Arch Int Med. 1997;157(15):1681-1686. doi: https://doi.org/10.1001/archinte.157.15.1681
18. Cryer P, Davis S, Shamoon H. Hypoglycemia in diabetes. Diabetes Care. 2003;26(6):1902-1912. doi: https://doi.org/10.2337/diacare.26.6.1902

19. Bloomfield HE, Greer N, Newman D. Predictors and consequences of severe hypoglycemia in adults with diabetes: a systematic review of the evidence. QUERI; 2012. Available from: https:// www.hsrd.research.va.gov/publications/esp/hypoglycemia-2012 REPORT.pdf

20. Desouza C, Salazar H, Cheong B, et al. Association of hypoglycemia and cardiac ischemia: a study based on continous monitoring. Diabetes Care. 2003:26:1485-1489. doi: https://doi.org/10.2337/diacare.26.5.1485

21. Shorr RI, Ray WA, Daugherty JR. Incidence and risk factors for serious hypoglycemia in older persons using insulin or sulfonylureas. Arch Intern Med. 1997;157:1681-1686. doi: https://doi.org/10.1001/archinte.1997.00440360095010

22. Berlin I, Sachon Cl, Grimaldi A. Identification of factors associated with impaired hypoglycaemia awareness in patients with type 1 and type 2 diabetes mellitus. Diabetes Metab. 2005;31(3 Pt 1):246-251. doi: https://doi.org/10.1016/s1262-3636(07)70191-x

23. Piątkiewicz P. Hypoglycemia in elderly type 2 diabetes patients. Diabetes Manag. 2016;6(3):071-075.

24. Bansal N, Dhaliwal R, Weinstock RS. Management of diabetes in the elderly. Med Clin North Am. 2015;99(2):351-377. doi: https://doi.org/10.1016/j.mcna.2014.11.008

25. Yaffe K, Falvey C, Hamilton N, et al. Diabetes, glucose control, and 9-year cognitive decline among older adults without dementia. Arch Neurol. 2012;69(9):1170-1175. doi: https://doi.org/10.1001/archneurol.2012.1117

26. Kosiborod M, Rathore SS, Inzucchi SE, et al. Admission glucose and mortality in elderly patients hospitalized with acute myocardial infarction: implications for patients with and without recognized diabetes. Circulation. 2005;111(23):3078-3086. doi: https://doi.org/10.1161/CIRCULATIONAHA.104.517839

27. Meneilly GS, Knip A, Miller DB, et al. Diabetes in older people diabetes Canada clinical practice guidelines expert committee. Can J Diabetes. 2018;42 Suppl 1:283-295. doi: https://doi.org/10.1016/j.jcjd.2017.10.021

28. UK Prospective Diabetes Study (UKPDS) Group. Intensive bloodglucose control with sulphonylureas or insulin compared with conventional treatment and risk of complications in patients with type 2 diabetes (UKPDS 33). Lancet. 1998;352:837-853. https://doi.org/10.1016/s0140-6736(98)07019-6

29. Клинические рекомендации «Алгоритмы специализированной медицинской помощи больных сахарным диабетом». / Под ред. И.И. Дедова, М.В. Шестаковой, А.Ю. Майорова. 9-й вып. - М., 2019. [Standards of specialized diabetes care. Ed. by Dedov II, Shestakova MV, Mayorov AYu. 9th Edition. Moscow; 2019. (In Russ).] doi: https://doi.org/10.14341/DM221S1

30. Inzucchi SE, Lipska KJ, Mayo H, et al. Metformin in patients with type 2 diabetes and kidney disease: a systematic review. JAMA. 2014;312(24):2668-2675. doi: https://doi.org/10.1001/jama.2014.15298

31. Markowicz-Piasecka M, Huttune MK, Lukasz M, et al. Is Metformin a perfect drug? Updates in pharmacokinetics and pharmacodynamics. Curr Pharm Des. 2017;23(17):2532-2550. doi: https://doi.org/10.2174/1381612822666161201152941

32. De Jager J, Kooy A, Lehert $P$, et al. Long term treatment with metformin in patients with type 2 diabetes and risk of vitamin B-12 deficiency: randomised placebo controlled trial. BMJ. 2010;340:c2181. doi: https://doi.org/10.1136/bmj.c2181

33. Sircar M, Bhatia A, Munshi M. Review of Hypoglycemia in the older adult: clinical implications and management. Can J Diabetes. 2016;40(1):66-72. doi: https://doi.org/10.1016/j.jcjd.2015.10.004

34. Mordarska K, Godziejewska-Zawada M. Diabetes in the elderly. Menopause Rev. 2017;16(2):38-43. doi: https://doi.org/10.5114/pm.2017.68589

35. Bohannon N. Overview of the gliptin class (dipeptidyl peptidase-4 inhibitors) in clinical practice. Postgrad Med. 2009;121(1):40-45. doi: https://doi.org/10.3810/pgm.2009.01.1953

36. Drucker DJ. Mechanisms of action and therapeutic application of glucagon-like peptide-1. Cell Metab. 2018 3;27(4):740-756. doi: https://doi.org/10.1016/j.cmet.2018.03.001 
37. Chrysant SG, Chrysant GS. Clinical implications of cardiovascular preventing pleiotropic effects of dipeptidyl peptidase-4 inhibitors. Am J Cardiol. 2012;109(11):1681-1685. doi: https://doi.org/10.1016/j.amjcard.2012.01.398

38. Deacon CF, Holst JJ. Dipeptidyl peptidase-4 inhibitors for the treatment of type 2 diabetes: comparison, efficacy and safety. Expert Opin Pharmacother. 2013:14(15):2047-2058. doi: https://doi.org/10.1517/14656566.2013.824966

39. Kim NH, Taeyang Yu T, Lee DH. The nonglycemic actions of dipeptidyl peptidase-4 inhibitors. Biomed Res Int. 2014;2014:368703. doi: https://doi.org/10.1155/2014/368703

40. Chrysant SG, Chrysant GS. Clinical implications of cardiovascular preventing pleiotropic effects of dipeptidyl peptidase-4 inhibitors. Am J Cardiol. 2012;109(11):1681-1685. doi: https://doi.org/10.1016/.amjcard.2012.01.398

41. Round EM, Engel SS, Golm GT, et al. Safety of sitagliptin in elderly patients with type 2 diabetes: a pooled analysis of 25 clinical studies Drugs Aging. 2014:31(3):203-214. doi: https://doi.org/10.1007/s40266-014-0155-7

42. Umezawa S, Kubota A, Maeda H, Kanamor A. Two-year assessment of the efficacy and safety of sitagliptin in elderly patients with type 2 diabetes: Post hoc analysis of the ASSET-K study. BMC Endocr Disord. 2015;15:34. doi: https://doi.org/10.1186/s12902-015-0033-2

43. Fukuda M, Doi K, Sugawara M, Mochizuki K. Efficacy and safety of sitagliptin in elderly patients with type 2 diabetes mellitus: a focus on hypoglycemia. J Diabetes Investig. 2019;10(2):383-391. doi: https://doi.org/10.1111/jdi.12915

44. Green JB, Bethel MA, Paul SK, et al. Rationale, design, and organization of a randomized, controlled trial evaluating cardiovascular outcomes with sitagliptin (tecos) in patients with type 2 diabetes and established cardiovascular risks. Am Heart J. 2013;166(6):983-989.e7. doi: https://doi.org/10.1016/j.ahj.2013.09.003

45. Green JB, Bethel MA, Armstrong PW, et al.; TECOS Study Group. Effect of sitagliptin on cardiovascular outcomes in type 2 diabetes. NEng/ J Med. 2015;373(3):232-242. doi: https://doi.org/10.1056/NEJMoa1501352

46. Arnets L, Hage C, Brismar K, Catrina SB, et al. Copeptin, insulinlike growth factor binding protein-1 and sitagliptin: A report from the BEta-cell function in Glucose abnormalities and Acute Myocardial Infarction study. Diab Vasc Dis Res. 2016;13(4):307-311. doi: https://doi.org/10.1177/1479164116635997

47. Al-Rasheed NM, Al-Rasheed NM, Hasan IH, et al. Sitagliptin attenuates cardiomyopathy by modulating the JAKJSTAT signaling pathway in experimental diabetic rats. Drug Des Devel Ther 2016;10:2095-2107. doi: https://doi.org/10.2147/DDDT.S109287.

48. Tremblay AJ, Lamarche B, Deacon CF, et al. Effects of sitagliptin therapy on markers of low-grade inflammation and cell adhesion molecules in patients with type 2 diabetes. Metabolism. 2014;63(9):1141-1148. doi: https://doi.org/10.1016/j.metabol.2014.06.004

49. Vittone F, Liberman A, Vasic D, et al. Sitagliptin reduces plaque macrophage content and stabilises arteriosclerotic lesions in Apoe (-/-) mice. Diabetologia. 2012;55(8):2267-2275.

doi: https://doi.org/10.1007/s00125-012-2582-5

50. Omoto S, Taniura T, Nishizawa T, et al. Antiatherosclerotic effects of sitagliptin in patients with type 2 diabetes mellitus. Diabetes Metab Syndr Obes. 2015;27(8):339-345. doi: https://doi.org/10.2147/dmso.s84545

51. Wang T, McNeill AM, Chen Y, et al. Characteristics of elderly patients initiating sitagliptin or non-dpp-4-inhibitor oral antihyperglycemic agents: analysis of a crosssectional us claims database. Diabetes Ther. 2018;9(1):309-315. doi: https://doi.org/10.1007/s13300-017-0360-6

52. Singh $H$, Chakrawarti $A$, Singh $H$, et al. Evaluation of treatment satisfaction, efficacy and safety of dipeptidyl peptidase-4 inhibitors in geriatric patients with type 2 diabetes mellitus: a cross-sectional comparative study. J Family Med Prim Care. 2018;7(1):70-76. doi: https://doi.org/10.4103/jfmpc.jfmpc_89_17

53. Russo GT, De Cosmo S, Viazzi F, et al. Diabetic kidney disease in the elderly: prevalence and clinical correlates. BMC Geriatr. 20182;18(1):38. doi: https://doi.org/10.1186/s12877-018-0732-4

54. Umemura T, Kawamura T, Umegaki H, et al. Association of chronic kidney disease and cerebral small vessel disease with cognitive impairment in elderly patients with type 2 diabetes. Dement Geriatr Cogn Dis Extra. 2013;3(1):212-222. doi: https://doi.org/10.1159/000351424

55. Liu W, Yu J, Yan Q et al. Meta-analysis of the benefit of sitagliptin treatment in patients with type 2 diabetes complicated with incipient nephropathy. Exp Ther Med. 2018;16(3):2545-2553. doi: https://doi.org/10.3892/etm.2018.6449

56. Wang D, Zhang G, Chen X, et al. Sitagliptin ameliorates diabetic nephropathy by blocking TGF- $\beta 1 / \mathrm{Smad}$ signaling pathway. Int J Mol Med. 2018;41(5):2784-2792. doi: https://doi.org/10.3892/ijmm.2018.3504

57. Migoya EM, Stevens $\mathrm{CH}$, Bergman AJ, et al. Effect of moderate hepatic insufficiency on the pharmacokinetics of sitagliptin. Can J Clin Pharmacol. 2009;16(1):e165-170.

58. Остроумова О.Д., Суркова Е.В., Ших Е.В., и др. Когнитивные нарушения у больных сахарным диабетом 2 типа: распространенность, патогенетические механизмы, влияние противодиабетических препаратов // Сахарный диабет. 2018. - T. 21. — №4. - C. 307-318. [Ostroumova OD, Surkova $\mathrm{EV}$, Chikh EV, et al. Cognitive impairment in patients with type 2 diabetes mellitus: prevalence, pathogenetic mechanisms, the effect of antidiabetic drugs. Diabetes mellitus. 2018;21(4):307-318. (In Russ).] doi: https://doi.org/10.14341/DM9660

59. Isik AT, Soysal P, Yay A, Usarel C. The effects of sitagliptin, a DPP4 inhibitor, on cognitive functions in elderly diabetic patient with or without Alzheimer's disease. Diabetes Res Clin Pract. 2017;123:192-198. doi: https://doi.org/10.1016/j.diabres.2016.12.010

60. Gault VA, Lennox R, Flatt PR. Sitagliptin, a dipeptidyl peptidase-4 inhibitor, improves recognition memory, oxidative stress and hippocampal neurogenesis and upregulates key genes involved in cognitive decline. Diabetes Obes Metab. 2015;17(4):403-413. doi: https://doi.org/10.1111/dom.12432

\section{ИНФОРМАЦИЯ ОБ АВТОРАХ [AUTHОRS INFO]}

Бирюкова Елена Валерьевна, д.м.н., профессор [Elena V. Biryukova, MD, PhD, Professor]; адрес: Россия, 127473 Москва, ул. Делегатская, д. 20, стр. 1 [address: 20c1, Delegatskaya street, 127473 Moscow, Russian Federation]; ORCID: https://orcid.org/0000-0001-9007-4123; eLibrary SPIN: 3700-9150; e-mail: lena@obsudim.ru

\section{ЦИТИРОВАТЬ:}

Бирюкова Е.В. Сахарный диабет 2 типа у лиц пожилого возраста в практике эндокринолога: фокус на ингибиторы ДПП-4 // Сахарный диабет. — 2019. — Т. 22. — №6. — С. 582-591. doi: https://doi.org/10.14341/DM10315

\section{TO CITE THIS ARTICLE:}

Biryukova EV. Type 2 diabetes mellitus in elderly patients treated with endocrinologists in clinical practice. Diabetes Mellitus. 2019;22(6):582-591. doi: https://doi.org/10.14341/DM10315 